\title{
Phenethyl isothiocyanate suppresses EGF-stimulated SAS human oral squamous carcinoma cell invasion by targeting EGF receptor signaling
}

\author{
HUI-JYE CHEN ${ }^{1}$, CHUNG-MING LIN ${ }^{5}$, CHAO-YING LEE ${ }^{2}$, NAI-CHEN SHIH ${ }^{3}$, \\ SAKAE AMAGAYA ${ }^{6}$, YUNG-CHANG LIN ${ }^{4}$ and JAI-SING YANG ${ }^{3}$
}

\begin{abstract}
${ }^{1}$ Graduate Institute of Molecular Systems Biomedicine, ${ }^{2}$ School of Pharmacy, ${ }^{3}$ Department of Pharmacology, China Medical University, Taichung 404; ${ }^{4}$ Departments of Veterinary Medicine, National Chung Hsing University, Taichung 402; ${ }^{5}$ Department of Biotechnology, Ming Chuan University, Taoyuan 333, Taiwan, R.O.C.; ${ }^{6}$ Department of Kampo Pharmaceutical Sciences, Nihon Pharmaceutical University, Saitama 362-0806, Japan
\end{abstract}

Received March 3, 2013; Accepted May 13, 2013

DOI: 10.3892/ijo.2013.1977

\begin{abstract}
Phenethyl isothiocyanate (PEITC) is a natural compound that is involved in chemoprevention as well as inhibition of cell growth and induction of apoptosis in several types of cancer cells. Previous studies have revealed that PEITC suppresses the invasion of AGS gastric and HT-29 colorectal cancer cells. However, the effects of PEITC on the metastasis of SAS oral cancer cells remain to be determined. Our results showed that PEITC treatment inhibited the invasion of EGF-stimulated SAS cells in a concentration-dependent manner, but appeared not to affect the cell viability. The expression and enzymatic activities of matrix metalloprotease-2 (MMP-2) and matrix metalloprotease-9 (MMP-9) were suppressed by PEITC. Concomitantly, we observed an increase in the protein expression of both tissue inhibitor of metalloproteinase-1 (TIMP-1) and -2 (TIMP-2) in treated cells. Furthermore, PEITC treatments decreased the protein phosphorylation of epidermal growth factor receptor (EGFR) and downstream signaling proteins including PDK1, PI3K (p85), AKT, phosphorylated IKK and IкB to inactivate NF- $\kappa B$ for the suppression of MMP-2 and MMP-9 expression. In addition, PEITC can trigger the MAPK signaling pathway through the increase in phosphorylated p38, JNK and ERK in treated cells. Our data indicate that PEITC is able to inhibit the invasion of EGF-stimulated SAS oral cancer cells by targeting EGFR and its downstream signaling molecules and finally lead to the reduced expression and enzymatic activities of both MMP-2 and MMP-9. These results suggest that PEITC is promising for the therapy of oral cancer metastasis.
\end{abstract}

Correspondence to: Dr Jai-Sing Yang, Department of Pharmacology, China Medical University, 91 Hsueh-Shih Road, Taichung 40402, Taiwan, R.O.C.

E-mail: jaising@mail.cmu.edu.tw

Key words: phenethyl isothiocyanate, EGFR, invasion, MMP-2, MMP-9, OSCC SAS cells

\section{Introduction}

Head and neck squamous cell carcinoma (HNSCC), including oral cancer, is the sixth most common malignancy in humans worldwide. Oral cancer (OC) is one of the most frequent types of HNSCC. Approximately 95\% of OCs are squamous cell carcinomas (OSCC) (1). Histologically, OSCCs are derived from the epithelium lining of the oral cavity and can occur at various sites in the oral cavity, including the lips, hard palate, gum and tongue (2), with a preference on the tongue and floor of the mouth. Each year, 405, 000 new cases of oral cancer (OSCC) are diagnosed and the number is still accumulating in many countries. In Taiwan, OSCC is the sixth leading cause of cancer death. Approximately 5,400 new cases are identified and 2,200 deaths per year and the incidence of OSCC has increased 6-fold during the past decade.

The main causes of oral cancer includes tobacco and alcohol consumption (3), diets poor in vitamin A and carotenoids, indoor air pollution and poor oral hygiene $(4,5)$. The occurrence of oral cancer in Taiwan is closely related to betel quid chewing, cigarette smoking and alcohol consumption (6). The standard treatments for patients with oral cancer include surgery, radiotherapy and chemotherapy (7). Despite the improvement in surgery and chemotherapy during the last 20 years (8), oral cancer remains a disease with poor prognosis and a low survival rate (9). In patients identified with an advanced stage of the disease, there is a high incidence of invasion to adjacent tissues, of metastasis to lymph node and distant areas and of recurrence during the patient's lifetime $(10,11)$. As compare to $90 \%$ of patients without metastasis, the 5-year survival rate for patients with lymph node metastasis at presentation is significantly reduced to $25-40 \%$ (12). Additionally, lymph node metastasis occurs in $\sim 40 \%$ of patients with oral cancer. Therefore, there is an urgent need to identify agents that can inhibit the invasion and metastasis of oral cancers.

The active components in natural products such as polyphenolic and isothiocyanate (ITC)-containing compounds are the intensive target of research for their promising cancer 
preventative and therapeutic properties $(13,14)$ and low toxicity to cells (15). Epidemiological investigations have reported an inverse relation between the dietary intake of fruits and vegetables, including cruciferous vegetables and the risk of various types of malignancies (16-18). The anti-carcinogenic effects of cruciferous vegetables such as broccoli (18) and watercress (19) have been ascribed to certain chemicals with the isothiocyanate $(-\mathrm{N}=\mathrm{C}=\mathrm{S})$ functional group $(19,20)$. Isothiocyanates are produced from the hydrolysis of the inactive precursor glucosinolates by myrosinase in cruciferous vegetables when the plant tissues are crushed or masticated (19-21). These isothiocyanates, which consist of phenethyl ITC (PEITC), allyl ITC (AITC), benzyl ITC (BITC) (22) and sulforaphane (SFN), have been shown to have potential cancer chemopreventive activity in a number of experimental models, including cancer of the esophagus, mammary gland, lung, liver, pancreas, fore-stomach, colon, small intestine and bladder of mice, rats, other rodents and colon cancer in humans (23-25).

PEITC, a member of isothiocyanate, possesses a variety of biological activities such as the induction of phase II detoxification enzymes, the inhibition of cytochrome P450 (CYP) enzymes (26), arrest of cell cycle (27) and stimulation of apoptosis (28-31), inhibition of nuclear factor- $\kappa \mathrm{B}$ $(\mathrm{NF}-\kappa \mathrm{B})$-regulated gene expression (32) and activation of Atg5-mediated autophagy (33) in different cancer cell lines. PEITC also suppresses the pulmonary neoplasia induced by 4-(methylnitrosamino)-1-(3-pyridyl)-1-butone in the lung of A/J mouse $(34,35)$, prevents the formation of colonic aberrant crypt foci induced by azoxymethane (36) and reduces the number and size of polyps in $\mathrm{Apc}^{\mathrm{Min} /+}$ mice (23). The incidence and burden (affected area) of poorly differentiated tumors in the dorsolateral prostate of transgenic adenocarcinoma of mouse prostate (TRAMP) model mice were reduced when given $3 \mu$ mole PEITC/kg of diet (37). Further, PEITC is currently in clinical trials for lung cancer (38). These effects suggest a potential role of PEITC in the suppression of tumorigenesis.

It has been shown that PEITC inhibited the migration and invasion of human gastric cancer AGS cells (39) and colon cancer HT29 cells (40). In addition, PEITC treatment reduced angiogenesis and cell motility of human umbilical vein endothelial cells and PC-3 prostate cancer cells (41). However, the effects and underlying mechanism of PEITC on the metastasis of oral squamous cell carcinomas are still not clear. In this study, we demonstrated that PEITC acted on the phosphorylation of EGFR and sequentially inactivated the PI3K/AKT kinase cascade, repressed the NF- $\kappa \mathrm{B}$-mediated signaling and hence reduced expression of matrix metalloproteases (MMPs), finally leading to the inhibition of OSCC invasion.

\section{Materials and methods}

Chemicals and reagents. Phenethyl isothiocyanate (PEITC) was purchased from Sigma-Aldrich (St. Louis, MO, USA). Antibodies against AKT, EGFR, ERK, IкB, JNK, MMP-2, MMP-9, p38, PI3K, TIMP-1, TIMP-2, $\beta$-actin and GAPDH were obtained from Santa Cruz Biotechnology (Santa Cruz, CA, USA). Antibodies against phospho-AKT (S308), phospho-
AKT (S473), phospho-EGFR (Y845), phospho-EGFR (Y992), phospho-EGFR (Y1068), phospho-ERK (Thr202/Tyr204), phospho-IKK, phospho-IкB, phospho-JNK (Thr183/Tyr185), phospho-PDK1, phospho-PI3K and phospho-p38 (Thr183/ Tyr185) were obtained from Cell Signaling Technology (Danvers, MA, USA). HRP-conjugated secondary antibodies such as rabbit anti-mouse IgG, goat anti-rabbit IgG and donkey anti-goat IgG were purchased from Santa Cruz Biotechnology. MTT (3-(4,5-dimethyl-2-thiazolyl)-2,5-diphenyl-2H-tetrazolium bromide) and epidermal growth factor (EGF) were obtained from Sigma-Aldrich. DMEM medium, fetal bovine serum (FBS), L-glutamine, penicillin-streptomycin and trypsin-EDTA were purchased from Gibco BRL (Invitrogen Life Technologies, Carlsbad, CA).

Cell culture. Human OSCC SAS cell line was cultured in DMEM medium supplemented with $10 \%$ of fetal bovine serum, $100 \mathrm{U} / \mathrm{ml}$ penicillin, $100 \mu \mathrm{g} / \mathrm{ml}$ streptomycin and $2 \mathrm{mM}$ glutamine and incubated at $37^{\circ} \mathrm{C}$ in a humidified chamber with $5 \% \mathrm{CO}_{2}(42)$.

Cell invasion assay. The membrane of each transwell insert was washed with 1X PBS and pre-coated with Matrigel (2 mg/ $\mathrm{ml}, 20 \mu \mathrm{l}$; BD Matrigel ${ }^{\mathrm{TM}}$ Invasion chamber). SAS cells $\left(2 \times 10^{4}\right)$ were seeded into the chamber of the insert and incubated with $0.5 \mathrm{ml}$ of complete DMEM medium in each transwell. Cells were treated with EGF (100 ng/ml) and various concentrations of PEITC $(0,0.5,1$ and $2 \mu \mathrm{M})$ for $48 \mathrm{~h}$ and then cells inside the chamber were removed by a cotton swab. Invaded cells were fixed with $4 \%$ formaldehyde in PBS and stained with $0.1 \%$ of hematoxylin, captured and the number of invaded cells was counted $(43,44)$.

Cell viability assay. SAS cells $\left(2 \times 10^{4}\right)$ were seeded into the 96-well plate and treated with EGF (100 ng/ml) and PEITC ( 0 , $0.5,1$ and $2 \mu \mathrm{M})$ for $48 \mathrm{~h}$. Medium was removed and replaced with fresh DMEM medium containing MTT $(0.5 \mathrm{mg} / \mathrm{ml})$ and cultured at $37^{\circ} \mathrm{C}$ incubator for an additional $4 \mathrm{~h}$. Medium was again removed and $200 \mu \mathrm{l}$ of DMSO was added into each well to dissolve the formazan crystals and the absorbance of each well was measured at $570 \mathrm{~nm}$ with a reference wavelength at $620 \mathrm{~nm}$ on an ELISA reader. The data of control sample $(0 \mu \mathrm{M}$ of PEITC) was set as $100 \%$ and the relative cell viability of drug-treated samples was calculated accordingly. Cell morphology was recorded by using a phase-contrast microscope $(43,44)$.

Gelatin zymography assay. SAS cells $\left(1 \times 10^{6}\right)$ were seeded into 12-well plate for $48 \mathrm{~h}$ and treated with EGF $(100 \mathrm{ng} / \mathrm{ml})$ and various concentrations of PEITC $(0,0.5,1$ and $2 \mu \mathrm{M})$ in serum-free DMEM medium for an additional $48 \mathrm{~h}$. Culture medium was spun at $1000 \mathrm{x}$ g for $10 \mathrm{~min}$ at $4^{\circ} \mathrm{C}$, supernatant was collected and protein concentration was determined as described below. $5 \mu \mathrm{g}$ of total proteins were mixed with $2 \mathrm{X}$ sample buffer $(0.125 \mathrm{M}$ Tris-HCl, $\mathrm{pH} 6.8,4 \% \mathrm{SDS}$, $20 \%$ glycerol, $0.01 \%$ bromophenol blue) and electrophoresed in an $8 \%$ SDS-polyacrylamide gel with $1 \%$ gelatin. Gel was incubated with $2.5 \%$ Triton X-100 at room temperature for $30 \mathrm{~min}$ to remove residual SDS and then incubated in Zymogen developing buffer (50 mM Tris, $\mathrm{pH}$ 7.5, $200 \mathrm{mM} \mathrm{NaCl}, 5 \mathrm{mM}$ 
$\mathrm{CaCl}_{2}, 1 \mu \mathrm{M} \mathrm{ZnCl}{ }_{2}, 0.02 \%$ Brij-35; Bio-Rad Laboratories, Hercules, CA, USA) at $37^{\circ} \mathrm{C}$ overnight. Gel was then washed extensively with water and stained with $0.5 \%$ Coomassie blue G-250 (0.5\% Coomassie blue G-250, 50\% methanol and $10 \%$ acetic acid) for $2 \mathrm{~h}$ and de-stained in de-staining solution (50\% methanol and $10 \%$ acetic acid) until clear zones were evident. The gel was scanned by a scanning digitizing system and digitized by using free Image $\mathbf{J}$ software (NIH) $(43,44)$.

Preparation of whole cell lysate. SAS cells were challenged with EGF $(100 \mathrm{ng} / \mathrm{ml})$ and treated with various concentrations of PEITC for the specified time and cells were collected for the preparation of whole cell lysate using iced-cold RIPA buffer (50 mM Tris-base, $150 \mathrm{mM} \mathrm{NaCl,} \mathrm{0.1 \%} \mathrm{SDS,} \mathrm{1 \%} \mathrm{sodium}$ deoxycholate, $1 \% \mathrm{NP}-40, \mathrm{pH} 7.5$ ) supplemented with protease inhibitors including leupeptin $(17 \mathrm{mg} / \mathrm{ml})$, sodium orthovanadate $(10 \mathrm{mg} / \mathrm{ml})$, phenylmethanesulfonyl fluoride $(10 \mathrm{mg} / \mathrm{ml})$. Cells were completely re-suspended in extraction buffer and kept in ice for $30 \mathrm{~min}$ with occasional mixing and cell lysate were collected by a spin at $12,000 \mathrm{xg}$ for $10 \mathrm{~min}$ at $4^{\circ} \mathrm{C}$. The protein concentrations present in the samples were measured by using Bio-Rad Protein Assay Dye Reagent Concentrate (Bio-Rad) (43,45).

Western blotting. The obtained whole cell lysate was resolved in sodium dodecyl sulfate-polyacrylamide gel and transferred onto polyvinylidene fluoride (PVDF) membrane (Millipore) by using the iBlot Dry Blotting Transfer System (Invitrogen/ Life Technologies). The transferred membranes were blocked in 5\% non-fat milk (prepared in Tris-buffered saline supplemented with $0.1 \%$ Tween-20; TBST) at ambient temperature for $1 \mathrm{~h}$ and incubated with primary antibody at $4^{\circ} \mathrm{C}$ overnight. Membranes were washed with TBST three times for $10 \mathrm{~min}$ before incubated with HRP-coupled secondary antibody for $1 \mathrm{~h}$. Protein signals were visualized by enhanced chemiluminescence (ECL) and exposed to Bio-MAX MR X-ray film (Eastman Kodak, Rochester, NY, USA) $(43,46,47)$.

Quantitative real-time PCR analyses. SAS cells were treated with 0,1 and $2 \mu \mathrm{M}$ of PEITC and EGF (100 ng/ml) for $24 \mathrm{~h}$ and cells were collected. Total RNAs were isolated using the Qiagen RNeasy mini Kit. cDNAs were synthesized using the High Capacity cDNA Reverse Transcription kit according to the supplier's brochure (Applied Biosystems). For the quantitative PCR reaction, $1 \mu \mathrm{l}$ of cDNAs were mixed with 2X SYBR Green PCR Master Mix (Applied Biosystems) and $200 \mathrm{nM}$ of forward and reverse primers (see below for detailed sequences). PCR reaction was performed on an Applied Biosystems 7300 Real-Time PCR system in triplicate according to the following conditions: $2 \mathrm{~min}$ at $50^{\circ} \mathrm{C}, 10 \mathrm{~min}$ at $95^{\circ} \mathrm{C}$ and 40 cycles of $15 \mathrm{sec}$ at $95^{\circ} \mathrm{C}, 1 \mathrm{~min}$ at $60^{\circ} \mathrm{C}$. Fold changes of the gene expression were derived using the comparative $\mathrm{C}_{T}$ method $(40,48)$. The used primer pairs were: human MMP-2-forward, 5'-CCCCAGACAGGTGATCTTGAC-3'; human MMP-2-reverse, 5'-GCTTGCGAGGGAAGAAGT TG-3'; human MMP-9-forward, 5'-CGCTGGGCTTAGAT CATTCC-3'; human MMP-9-reverse, 5'-AGGTTGGATACAT CACTGCATTAGG-3'; human GAPDH-forward, 5'-ACACC CACTCCTCCACCTTT-3'; human GAPDH-reverse, 5'-TAGC CAAATTCGTTGTCATACC-3' (49).
Immunofluorescence staining. SAS cells were seeded onto slides overnight and incubated with EGF (100 ng/ml) and PEITC $(0,1$ and $2 \mu \mathrm{M})$ for $6 \mathrm{~h}$. Cells were fixed in $4 \%$ formaldehyde at room temperature for $15 \mathrm{~min}$, washed with PBS and permeabolized with $0.1 \%$ Triton X-100 in PBS for $15 \mathrm{~min}$, then incubated with primary antibodies at $4^{\circ} \mathrm{C}$ overnight. After extensive washes, cells were incubated with FITC-conjugated secondary antibodies for $2 \mathrm{~h}$. Cells were sealed and images were acquired with a fluorescence microscope (Nikon) and processed in Photoshop 7.0 software (50).

Statistical analysis. One-way ANOVA followed by Student's t-test was used to evaluate the differences between treated and experimental groups. $\mathrm{p}<0.05$ was considered to define a statistically significant difference $(49,51)$.

\section{Results}

PEITC inhibits EGF-stimulated invasion of SAS cells. We therefore determined the effects of PEITC on EGF-stimulated SAS cells. EGF-treatment increased the invasion of SAS cells, as revealed by Matrigel invasion assay (Fig. 1A). Treatment of EGF-stimulated SAS cells with PEITC decreased the invasion of cells in a concentration-dependent manner (Fig. 1A). From Fig. 1A, we have known that PEITC inhibited the invasion of EGF-stimulated SAS cells, a result that could be due to the inhibition of PEITC on the viability of EGF-stimulated cells. To test this, we treated EGF-stimulated SAS cells with different concentrations $(0,0.5,1$ and $2 \mu \mathrm{M})$ of PEITC and performed MTT cell viability assay. The result showed that PEITC at $0.5-2 \mu \mathrm{M}$ of concentrations did not inhibit the viability of EGF-stimulated SAS cells, as compared to cells without drug treatment (Fig. 1B). The cell morphology was comparable between treatments with 0 and $2 \mu \mathrm{M}$ of PEITC (see inserts in Fig. 1B).

PEITC inhibits the enzymatic activities and gene expression of MMP-2 and MMP-9 in EGF-stimulated SAS cells. Studies have shown that matrix metalloproteinases including MMP-2 (gelatinase A) and MMP-9 (gelatinase B) are expressed in oral cancers. These two MMPs are closely linked to the malignant potential of tumor cells and are also important for tumor invasion and metastasis $(44,52)$. To evaluate the effects of PEITC on the enzymatic activities of MMP-2 and MMP-9, we treated EGF-stimulated SAS cells with different concentrations $(0,0.5,1$ and $2 \mu \mathrm{M})$ of PEITC and assessed the enzymatic activities of MMP-2 and MMP-9 by gelatin zymography. As shown in Fig. 2A, treatments of cells with PEITC suppressed the enzymatic activities of both MMP-2 and MMP-9 in a concentration-dependent manner. Pronounced inhibition of the activities was observed at concentrations $>1 \mu \mathrm{M}$ of PEITC (see columns 3 and 4 and inserts of Fig. 2A). To address whether the inhibition of MMP-2 and MMP-9 was at the transcriptional level, we treated EGF-stimulated cells with PEITC $(0,1$ and $2 \mu \mathrm{M})$ and the effects of PEITC were analyzed by quantitative RT-PCR. As shown in Fig. 2B, treatment of PEITC significantly decreased the gene expression of both MMP-2 and MMP-9 in a concentration-dependent fashion. Taken together, these data suggested that both gelatinases (MMP-2 and MMP-9) are involved in the EGF-induced invasion of SAS cells. 

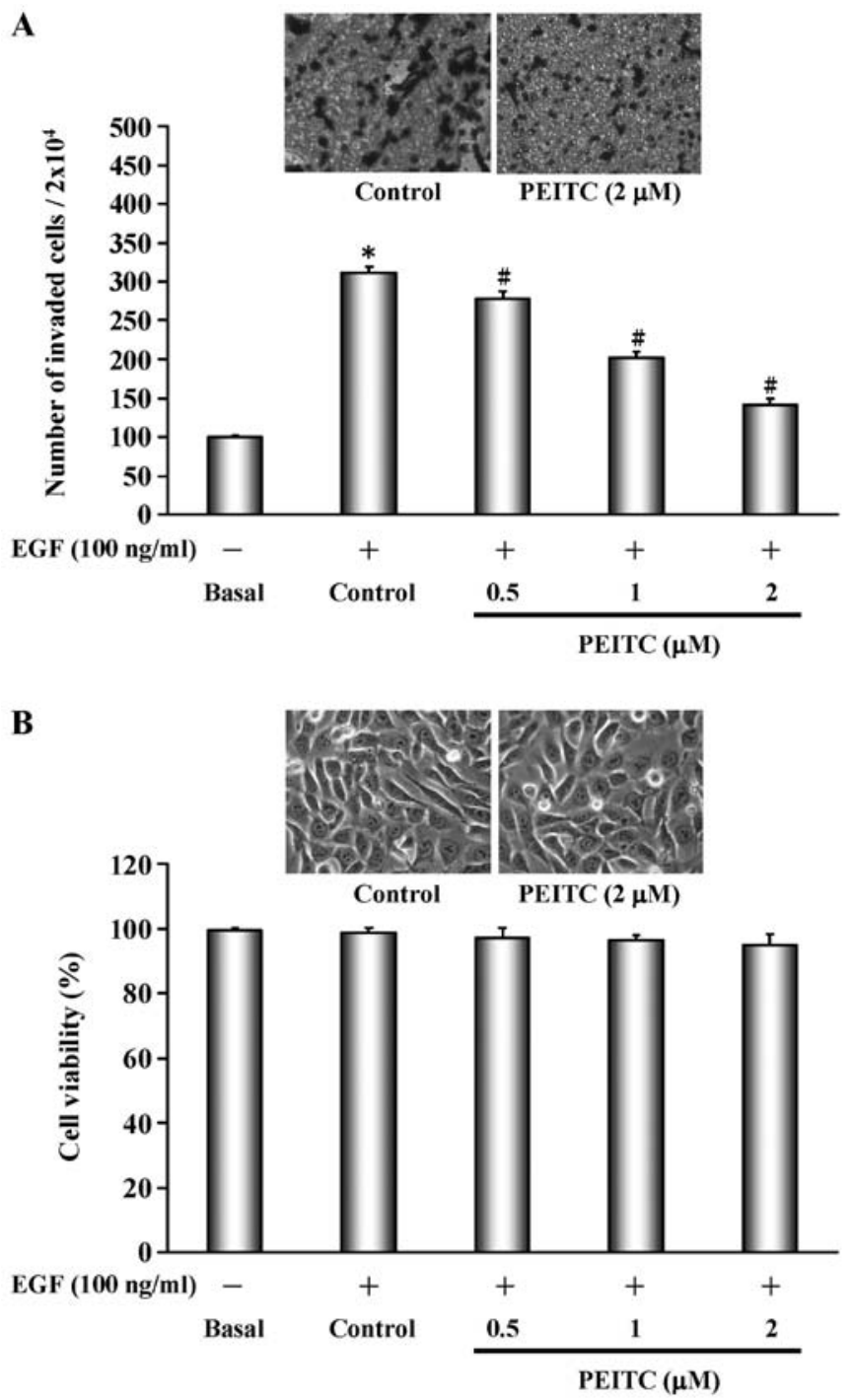

Figure 1. The effects of PEITC on invasion and viability of EGF-stimulated SAS cells. (A) PEITC inhibited the cell invasion of EGF-stimulated SAS cells. Cells were incubated in drug-free medium (basal) or treated with PEITC $(0,0.5,1$ and $2 \mu \mathrm{M})$ in medium containing EGF $(100 \mathrm{ng} / \mathrm{ml})$ for $48 \mathrm{~h}$ and cells that invaded through Matrigel into the lower surface of the filter were stained and counted. Inserts, images display the results of treatments with 0 (control) and $2 \mu \mathrm{M}$ of PEITC. ${ }^{*} \mathrm{P}<0.05$, as compared to the treatment in basal medium. ${ }^{\prime \prime} \mathrm{P}<0.05$, as compared to the treatment with $0 \mu \mathrm{M}$ of PEITC (control) in EGF-containing medium. (B) PEITC did not affect the cell viability of EGF-stimulated SAS cells. Cells were treated with PEITC $(0,0.5$, 1 and $2 \mu \mathrm{M})$ in the presence of EGF $(100 \mathrm{ng} / \mathrm{ml})$ for $48 \mathrm{~h}$ and cell viability was determined by MTT assay as described in Materials and methods. The cell viability is expressed as percentage by setting control treatment as $100 \%$. Each point is the mean $\pm \mathrm{SD}$ of three repeats. Inserts, images display the cell morphology of treatments with 0 and $2 \mu \mathrm{M}$ of PEITC.

PEITC inhibits the protein expression of MMP-1,MMP-2 and increased the protein expression of TIMP-1 and TIMP-2 in EGF-stimulated SAS cells. Since PEITC inhibited the enzymatic activities and gene expression of MMP-2 and MMP-9 in EGF-stimulated cells, we infered that PEITC could inhibit the protein expression of both metalloproteinases. As shown in Fig. 3A, treatment of EGF-stimulated SAS cells with PEITC $(1$ and $2 \mu \mathrm{M})$ reduced the protein expression of MMP-2 and MMP-9. It is well known that tissue inhibitor of metalloproteinases (TIMPs), TIMP-1 and TIMP-2, can bind and inhibit the enzymatic activities of MMP-2 and MMP-9 (53). We there-

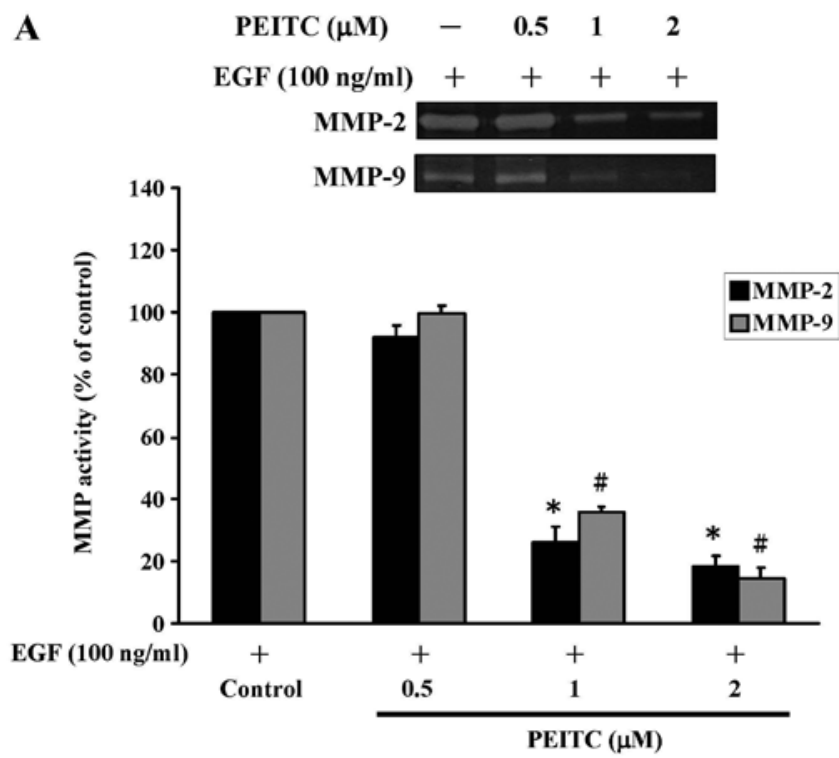

B

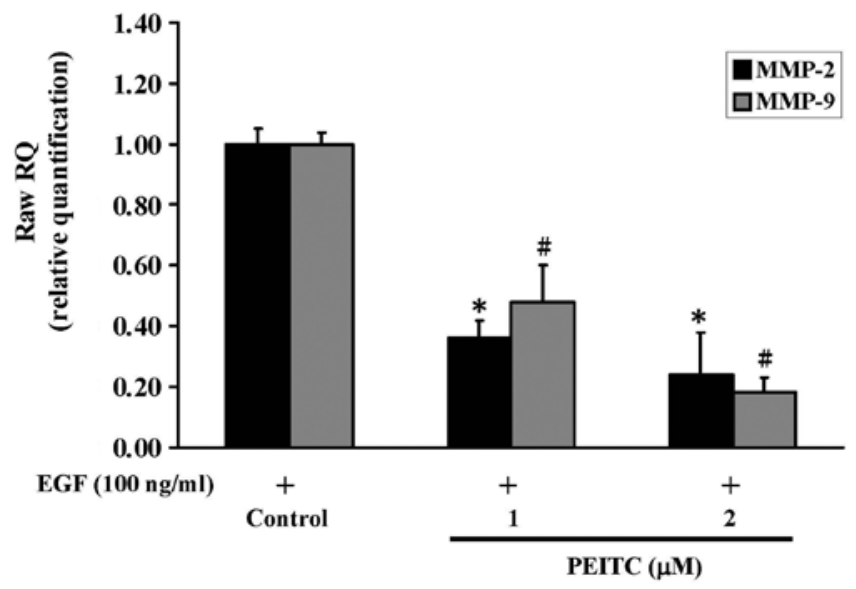

Figure 2. PEITC inhibits the EGF-stimulated enzymatic activities and gene expression of MMP-2 and MMP-9 of SAS cells. (A) PEITC inhibited the EGF-induced enzymatic activities of MMP-2 and MMP-9. Cells were treated with different concentrations of PEITC $(0,0.5,1$ and $2 \mu \mathrm{M})$ in the presence of EGF $(100 \mathrm{ng} / \mathrm{ml})$ for $48 \mathrm{~h}$. The conditioned media were collected for gelatin zymography assay to determine the MMP-2 and MMP-9 activities. Shown here are the densitometric data expressed as the mean \pm SD of three independent experiments. Enzymatic activity from control treatment $(0 \mu \mathrm{M})$ was set as $100 \%$ and the percentage of higher drug concentrations was calculated consequently. ${ }^{*} \mathrm{P}<0.05$, a significant statistical difference compared to the enzymatic activity of MMP-2 without PEITC treatment (control). ${ }^{~} \mathrm{P}<0.05$, a significant statistical difference compared to the enzymatic activity of MMP-9 without PEITC treatment (control). (B) PEITC decreased the gene expression of $M M P-2$ and $M M P-9$. Cells were treated with different concentrations of PEITC $(0,1$ and $2 \mu \mathrm{M})$ in the presence of EGF $(100 \mathrm{ng} / \mathrm{ml})$ for $24 \mathrm{~h}$ and gene expression of $M M P-2$ and $M M P-9$ was analyzed by quantitative RT-PCR. Gene expression of both control treatments were set as 1.0. Each point is the mean $\pm \mathrm{SD}$ of three experiments. " $\mathrm{P}<0.05$, a significant statistical difference compared to the gene expression of MMP-2 without PEITC treatment (control). ${ }^{~} \mathrm{P}<0.05$, a significant statistical difference compared to the gene expression of MMP-9 without PEITC treatment (control).

fore examined the protein expression of TIMP-1 and TIMP-2 in EGF-stimulated cells treated with PEITC $(0,1$ and $2 \mu \mathrm{M})$. The result showed that treatment with PEITC significantly increased the protein expression of TIMP-1 and TIMP-2 (Fig. 3A). These data suggested that PEITC can suppress the gene expression and protein expression of MMP-2 and MMP-9 
A

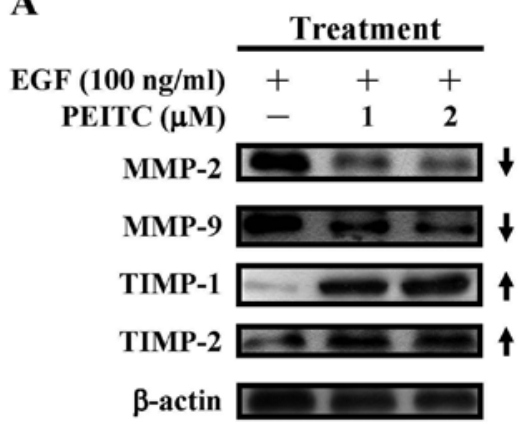

B

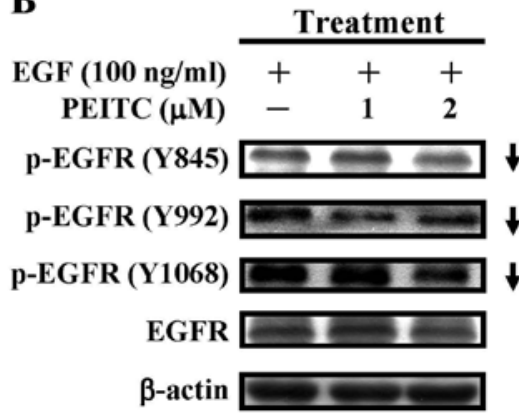

Figure 3. PEITC inhibits the expression of metalloproteases MMP-2, MMP-9 and induces the expression of tissue inhibitor of metalloproteinases TIMP-1 and TIMP-2 through inactivation of the epidermal growth factor receptor (EGFR) in EGF-stimulated SAS cells. (A) The effects of PEITC on the expression of MMP-2, MMP-9, TIMP-1 and TIMP-2 proteins in EGFstimulated SAS cells. Cells were treated with EGF $(100 \mathrm{ng} / \mathrm{ml})$ and PEITC $(0,1$ and $2 \mu \mathrm{M})$ for $48 \mathrm{~h}$ and cells were harvested for western blot analyses with MMP-2, MMP-9, TIMP-1 and TIMP-2 antibodies, respectively. The $\beta$-actin served as the loading control. (B) The effects of PEITC on the activation of the epidermal growth factor receptor (EGFR) in EGF-stimulated SAS cells. Cells were treated with EGF $(100 \mathrm{ng} / \mathrm{ml})$ and PEITC $(0,1$ and $2 \mu \mathrm{M})$ for $6 \mathrm{~h}$ and cell lysates were subjected to western blot analyses and detected with p-EGFR (Y845), p-EGFR (Y992), p-EGFR (Y1068) and EGFR antibodies, respectively. The $\beta$-actin served as the loading control.

and increase the protein expression of TIMP-1 and TIMP-2, leading to the decrease in the enzymatic activities of MMP-2 and MMP-9 in EGF-stimulated SAS cells.
PEITC suppressed the activation of EGFR. Binding of EGF to its cognate receptor EGFR results in the activation of EGFR that involves the autophosphorylation of EGFR and activation of intracellular signaling pathways, such as activation of PI3K/AKT, mitogen-activated protein kinases (MAPKs) and the signal transducer and activators of transcription (STATs) pathways, leading to cell proliferation and survival, invasion, metastasis and angiogenesis (54-56). Thus, we determined the effects of PEITC on the activation of EGFR proteins by examining the tyrosine phosphorylation of EGFR in EGF-challenged SAS cells. As shown in Fig. 3B, PEITC treatment ( 1 and $2 \mu \mathrm{M}$ ) inhibited the tyrosine phosphorylation of EGFR at Y845, Y992 and Y1068 concentration-dependently, while the protein levels of total EGFR remained largely unchanged. Immuno-fluorescent staining with anti-p-EGFR (Y1068) and anti-p-EGFR (Y845) also showed that tyrosine-phosphorylated EGFRs at Y1068 and Y845 were dramatically reduced in EGF-challenged cells treated with PEITC (Fig. 4). These data suggested that PEITC treatment suppressed the activation of EGFR in EGF-challenged SAS cells.

PEITC decreases the protein phosphorylation of PI3K, $A K T, I K K$ and I $K B \alpha$ in EGF-stimulated SAS cells. Since treatment with PEITC suppressed the activation of EGFR in EGF-challenged cells (Figs. 3B and 4), we next examined the effects of PEITC on downstream PI3K/AKT and NF- $\kappa$ B signaling pathways. PEITC treatment $(1$ and $2 \mu \mathrm{M})$ reduced the protein phosphorylation of PDK1, PI3K (p85) and profoundly reduced the protein phosphorylation of AKT (S308) and AKT (S473) in EGF-challenged cells (Fig. 5A, panels 1, 2, 4 and 5). Total proteins of PI3K (p85) was not changed during drug treatment, although total proteins of AKT were slightly reduced at $2 \mu \mathrm{M}$ of PEITC. In addition, PEITC treatment (1 and $2 \mu \mathrm{M}$ ) decreased the protein phosphorylation of IKK and of $\operatorname{I\kappa } B \alpha$, while increased the protein stability of $\mathrm{I} \kappa \mathrm{B} \alpha$. These data indicated that PI3K/AKT and NF- $\mathrm{KB}$ signaling pathway downstream of EGFR signaling is downregulated by PEITC treatment.
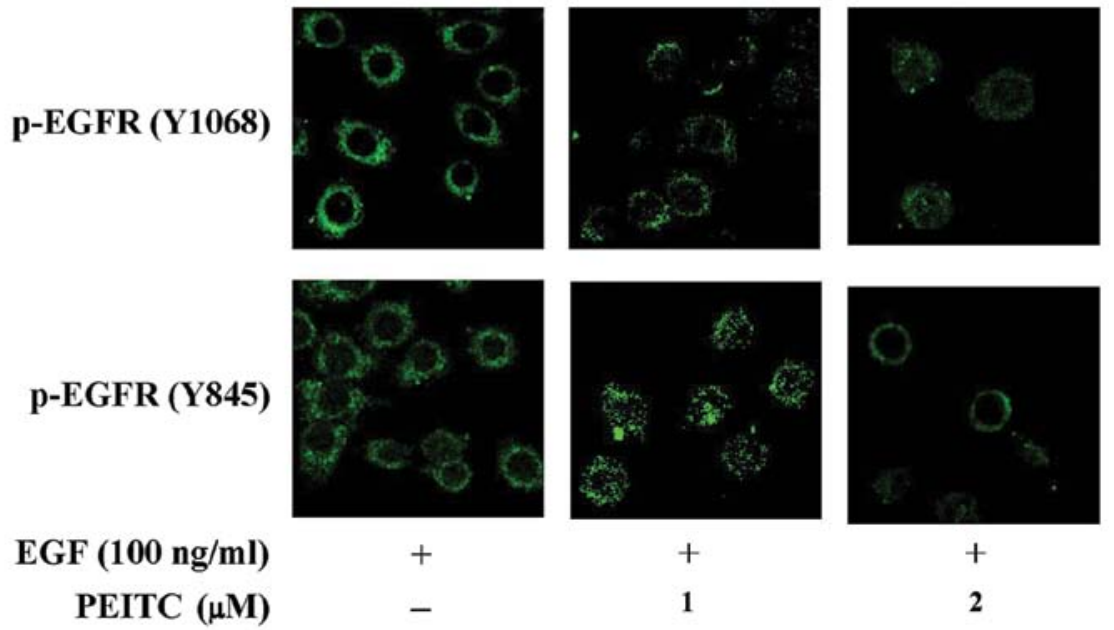

Figure 4. PEITC suppresses the phosphorylation of EGFR in EGF-stimulated SAS cells by immuno-fluorescent staining. Cells were treated with EGF $(100 \mathrm{ng} / \mathrm{ml})$ and PEITC $(0,1$ and $2 \mu \mathrm{M})$ for $6 \mathrm{~h}$, fixed and stained with anti-p-EGFR (Y845) and anti-p-EGFR (Y1068), followed by staining with FITCcoupled goat anti-mouse antibodies. 
A

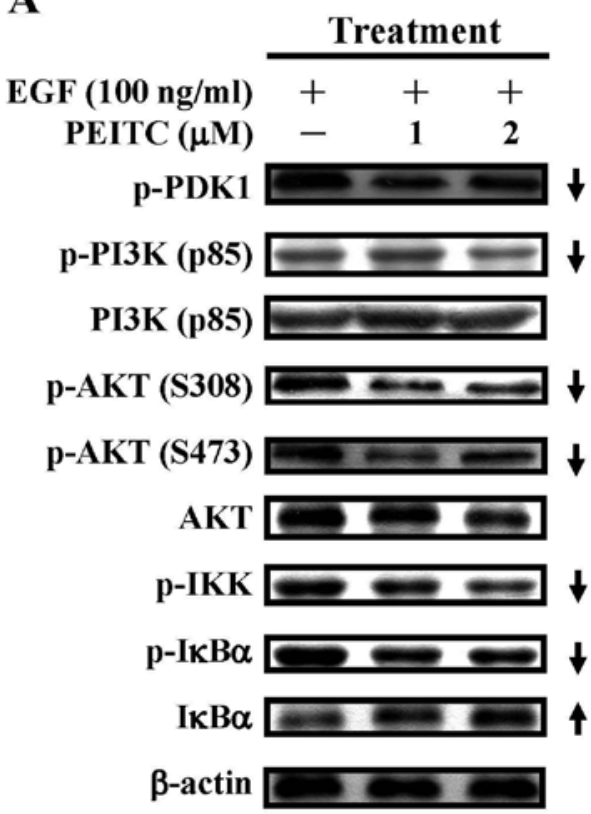

B

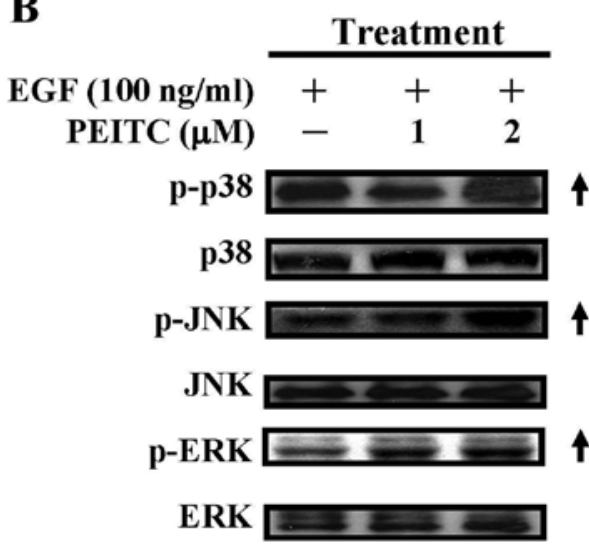

$\beta$-actin

Figure 5. The effects of PEITC on the PI3K/AKT and MAPK signaling pathways in EGF-stimulated SAS cells. Cells were treated with EGF (100 ng/ $\mathrm{ml})$ as well as PEITC $(0,1$ and $2 \mu \mathrm{M})$ for $6 \mathrm{~h}$ and cell lysates were prepared for the western blot analyses of (A) phosphorylated PDK1, PI3K (p85), phosphorylated PI3K (p85), AKT, phosphorylated AKT (S308 and S473),

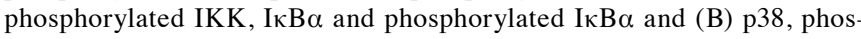
phorylated p38, JNK, phosphorylated JNK, ERK and phosphorylated ERK respectively. The $\beta$-actin served as the loading control.

The effects of PEITC on the MAPK signaling pathway in $E G F$-stimulated SAS cells. We also determined the effects of PEITC on the MAPK signaling pathways-p38, JNK and ERK signaling pathways downstream of EGFR activation. PEITC treatment $(1$ and $2 \mu \mathrm{M})$ increased the protein phosphorylation of p38 at higher drug concentration $(2 \mu \mathrm{M})$ (Fig. 5B, top panel). PEITC treatment ( 1 and $2 \mu \mathrm{M})$ also increased the protein phosphorylation of JNK and ERK in a concentrationdependent manner. The protein expression of $\mathrm{p} 38, \mathrm{JNK}$ and ERK appeared not to be affected (Fig. 5B, panels 2, 4 and 6), suggesting that the MAPK signaling pathway can be activated after PEITC treatment.

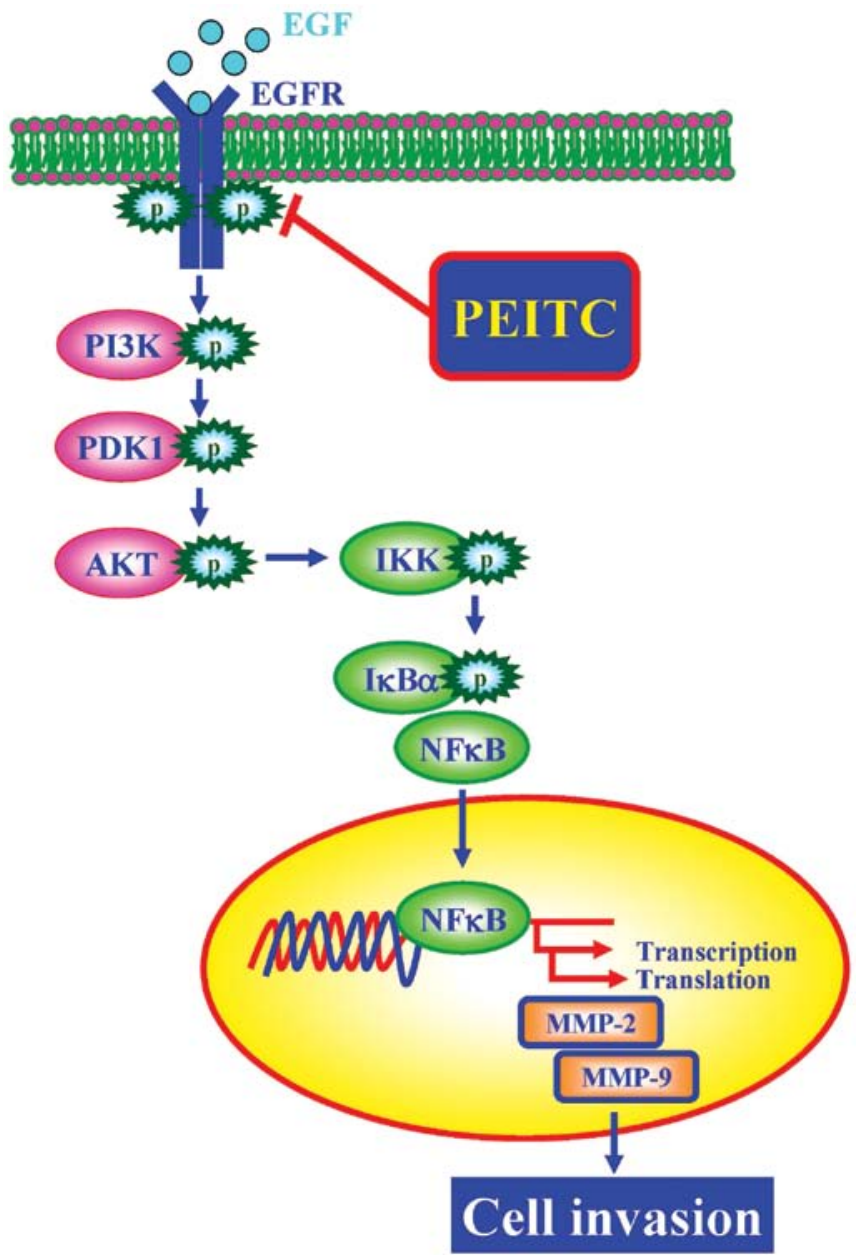

Figure 6. A model depicting the molecular mechanisms of PEITC on the inhibition of EGF-stimulated SAS cell invasion.

\section{Discussion}

Oral squamous cell carcinoma (OSCC) is a leading cause of cancer deaths in the world, characterized by poor prognosis and a low survival rate in spite of advances in treatment with surgery and radiotherapy. The main cause of death in OSCC is metastasis which primarily occurs through the lymphatic system. Once it has metastasized to the lymph nodes, the overall mortality rate of the disease is high and the 5-year overall survival rate does not exceed $50 \%$, which is one of the lowest rates for all major cancers $(10,57)$. Therefore, identification of new drugs for the chemotherapy of OSCC metastasis is highly desirable.

The epidermal growth factor receptor (EGFR) belongs to the HER/ErbB protein family of receptor tyrosine kinases. The EGFR gene encodes a 170-kDa transmembrane glycoprotein with its tyrosine kinase domain located within the cytoplasmic region. Ligand binding induces the activation of tyrosine kinase activity that triggers intracellular signaling cascades, including the Ras-Raf-mitogen-activated protein kinase pathway, the phosphatidylinositol 3-kinase-AKT pathway and the signal transducer and activators of transcription pathway, which contribute to cell proliferation and survival (58). Dysregulation in the signaling of EGFR and 
other members of the tyrosine kinase receptor family has been linked to cell transformation, autonomous cell growth, angiogenesis, invasion and metastases in a number of cancers (59). Up to $90 \%$ of head and neck squamous cell carcinoma (HNSCC) patients are identified with EGFR overexpression, which is considered to be involved in tumorigenesis and metastasis (60). Overexpression of EGFR in HNSCC is often associated with the simultaneous increase in its ligands such as the transforming growth factor $\alpha(54,61)$, which will lead to excessive activation of EGFR signaling either in an autocrineor paracrine-dependent manner. Thus, EGFR appears to be a promising therapeutic target for oral cancer metastasis (44). Our data indicated that PEITC can inhibit the EGF-induced invasion of SAS cells through the inactivation of EGFR and downstream signaling, including the suppression in the phosphorylation cascade of PI3K, PDK1 and AKT and hence the reduction of phosphorylated IKK, the decrease in the phosphorylation of $\mathrm{I} \kappa \mathrm{B}$ and the simultaneous increase in the stability of $\mathrm{I} \kappa \mathrm{B}$ and the block in the release and activation of NF- $\mathrm{BB}$. These results are consistent with previous studies using prostate cancer PC-3 cells $(32,62)$.

Matrix metalloproteases (MMPs) are responsible for the degradation of the extracellular matrix and facilitating spreading and metastasis of tumor cells. They are strongly blocked by the endogenous tissue inhibitors of metalloproteinases (TIMP-1, -2, -3 and -4). The expression of MMP-2 and MMP-9 was shown to be associated with tumor invasion and lymph node metastasis of oral cancer (63). The expression can also be regulated by $\mathrm{NF}-\kappa \mathrm{B}$ as their promoters possess $\mathrm{NF}-\kappa \mathrm{B}$ binding sites. As expected, the activities and expression of MMP-2 and MMP-9 were downregulated after PEITC treatment in EGF-stimulated SAS cells (Figs. 2 and 3A). These results could be due to the inactivation of $N F-\kappa B$ caused by the disruption in the EGFR signaling after PEITC treatment, leading to the failure in the expression of MMP-2 and MMP-9. Concomitantly, the increase in the expression of MMP-2 and -9 inhibitors, TIMP-1 and -2 proteins, was observed (Fig. 3A). These data suggested that PEITC suppressed the invasion and metastasis of EGFR-overexpressed oral cancers by reducing the expression and activities of MMP-2 and MMP-9 through the interference with the phosphorylation of EGFR and downstream signaling.

The other major downstream pathway regulated by EGFR is MAPK. Our finding that the phosphorylation of p38, JNK and ERK was increased after PEITC treatment in SAS cells is contradictory to the previous reports that PEITC can suppress the MAPK activation to inhibit the invasion and metastasis of HT-29 colon cancer cells and AGS gastric cancer cells $(39,40)$. These discrepancies could be due to cell type-specific effects. Alternatively, it has been reported that PEITC can induce cell apoptosis through the activation of MAPK $(29,64-68)$ and this raises the possibility that PETIC may trigger apoptosis in addition to the suppression of invasion and metastasis in our system. However, our data showed that the cell viability was not affected after PEITC treatment (1-2 $\mu \mathrm{M})$ (Fig. 1B). This suggests that the activation of MAPK by PEITC may elicit the downstream signaling and drive specific genes expression to repress the invasion and metastasis of OSCC, but not to cause apoptosis. Further detailed mechanism needs to be elucidated.
In conclusion, the signaling pathway underlying the effects of PEITC on the invasion of EGF-stimulated SAS cells is shown in Fig. 6. PEITC suppressed the phosphorylation and activation of EGFR and inhibited the sequential phosphorylation and activation of PI3K, PDK1 and AKT, resulting in the reduced expression of phosphorylated IKK and hence the reduced protein phosphorylation and increased protein stability of $\mathrm{I} \kappa \mathrm{B} \alpha$, which in turn suppressed the expression and enzymatic activities of MMP-2 and MMP-9, contributing to the inhibition of invasion in EGF-challenged SAS cells. Our data suggested that PEITC will be a promising therapeutic agent for the treatment of oral cancer metastasis.

\section{Acknowledgements}

This study was supported in part by research grants from the National Science Council of the Republic of China (NSC 101-2313-B-039-008) awarded to J.-S. Yang. This study was also supported in part by grant from China Medical University CMU101-S-27 awarded to J.-S. Yang and CMU98-N1-16 to H.-J. Chen.

\section{References}

1. Noguti J, De Moura CF, De Jesus GP, et al: Metastasis from oral cancer: an overview. Cancer Genomics Proteomics 9: 329-335, 2012.

2. Sarode SC, Sarode GS, Karmarkar S and Tupkari JV: A new classification for potentially malignant disorders of the oral cavity. Oral Oncol 47: 920-921, 2011.

3. Seethala RR, Gooding WE, Handler PN, et al: Immunohistochemical analysis of phosphotyrosine signal transducer and activator of transcription 3 and epidermal growth factor receptor autocrine signaling pathways in head and neck cancers and metastatic lymph nodes. Clin Cancer Res 14: 1303-1309, 2008.

4. Franceschi S, Bidoli E, Baron AE, et al: Nutrition and cancer of the oral cavity and pharynx in north-east Italy. Int J Cancer 47: 20-25, 1991.

5. Velly AM, Franco EL, Schlecht N, et al: Relationship between dental factors and risk of upper aerodigestive tract cancer. Oral Oncol 34: 284-291, 1998.

6. Ko YC, Huang YL, Lee CH, Chen MJ, Lin LM and Tsai CC: Betel quid chewing, cigarette smoking and alcohol consumption related to oral cancer in Taiwan. J Oral Pathol Med 24: 450-453, 1995.

7. Ichimiya Y, Fuwa N, Kamata M, et al: Treatment results of stage I oral tongue cancer with definitive radiotherapy. Oral Oncol 41: 520-525, 2005.

8. $\mathrm{Xi} \mathrm{S}$ and Grandis JR: Gene therapy for the treatment of oral squamous cell carcinoma. J Dent Res 82: 11-16, 2003.

9. Pereira MC, Oliveira DT, Landman G and Kowalski LP: Histologic subtypes of oral squamous cell carcinoma: prognostic relevance. J Can Dent Assoc 73: 339-344, 2007.

10. Parkin DM, Bray F, Ferlay J and Pisani P: Global cancer statistics, 2002. CA Cancer J Clin 55: 74-108, 2005.

11. Okura M, Aikawa T, Sawai NY, Iida S and Kogo M: Decision analysis and treatment threshold in a management for the N0 neck of the oral cavity carcinoma. Oral Oncol 45: 908-911, 2009.

12. Greenberg JS, Fowler R, Gomez J, et al: Extent of extracapsular spread: a critical prognosticator in oral tongue cancer. Cancer 97: 1464-1470, 2003.

13. Stan SD, Kar S, Stoner GD and Singh SV: Bioactive food components and cancer risk reduction. J Cell Biochem 104: 339-356, 2008.

14. Stan SD, Singh SV and Brand RE: Chemoprevention strategies for pancreatic cancer. Nat Rev Gastroenterol Hepatol 7: 347-356, 2010.

15. Keum YS, Jeong WS and Kong AN: Chemopreventive functions of isothiocyanates. Drug News Perspect 18: 445-451, 2005. 
16. Ambrosone CB, McCann SE, Freudenheim JL, Marshall JR Zhang Y and Shields PG: Breast cancer risk in premenopausal women is inversely associated with consumption of broccoli, a source of isothiocyanates, but is not modified by GST genotype. J Nutr 134: 1134-1138, 2004

17. Greenwald P, Clifford CK and Milner JA: Diet and cancer prevention. Eur J Cancer 37: 948-965, 2001.

18. Conaway CC, Yang YM and Chung FL: Isothiocyanates as cancer chemopreventive agents: their biological activities and metabolism in rodents and humans. Curr Drug Metab 3: 233-255, 2002.

19. Hecht SS: Inhibition of carcinogenesis by isothiocyanates. Drug Metab Rev 32: 395-411, 2000.

20. Fahey JW, Zalcmann AT and Talalay P: The chemical diversity and distribution of glucosinolates and isothiocyanates among plants. Phytochemistry 56: 5-51, 2001.

21. Hayes JD, Kelleher MO and Eggleston IM: The cancer chemopreventive actions of phytochemicals derived from glucosinolates. Eur J Nutr 47 (Suppl 2): 73-88, 2008.

22. Kumar A and Sabbioni G: New biomarkers for monitoring the levels of isothiocyanates in humans. Chem Res Toxicol 23 . 756-765, 2010.

23. Khor TO, Cheung WK, Prawan A, Reddy BS and Kong AN: Chemoprevention of familial adenomatous polyposis in $\mathrm{Apc}(\mathrm{Min} /+)$ mice by phenethyl isothiocyanate (PEITC). Mol Carcinog 47: 321-325, 2008.

24. Moy KA, Yuan JM, Chung FL, et al: Urinary total isothiocyanates and colorectal cancer: a prospective study of men in Shanghai, China. Cancer Epidemiol Biomarkers Prev 17: 1354-1359, 2008.

25. Hecht SS: Chemoprevention by isothiocyanates. J Cell Biochem (Suppl 22): 195-209, 1995.

26. Zhang Y: Cancer-preventive isothiocyanates: measurement of human exposure and mechanism of action. Mutat Res 555 $173-190,2004$

27. Xiao D, Johnson CS, Trump DL and Singh SV: Proteasomemediated degradation of cell division cycle 25C and cyclin-dependent kinase 1 in phenethyl isothiocyanate-induced G2-M-phase cell cycle arrest in PC-3 human prostate cancer cells. Mol Cancer Ther 3: 567-575, 2004.

28. Huong le D, Shim JH, Choi KH, et al: Effect of beta-phenylethyl isothiocyanate from cruciferous vegetables on growth inhibition and apoptosis of cervical cancer cells through the induction of death receptors 4 and 5. J Agric Food Chem 59: 8124-8131, 2011

29. Yan $\mathrm{H}$, Zhu Y, Liu B, et al: Mitogen-activated protein kinase mediates the apoptosis of highly metastatic human non-smal cell lung cancer cells induced by isothiocyanates. Br J Nutr 106 1779-1791, 2011.

30. Chen YR, Han J, Kori R, Kong AN and Tan TH: Phenylethyl isothiocyanate induces apoptotic signaling via suppressing phosphatase activity against c-Jun N-terminal kinase. J Biol Chem 277: 39334-39342, 2002.

31. Hwang ES and Lee HJ: Effects of phenylethyl isothiocyanate and its metabolite on cell-cycle arrest and apoptosis in LNCaP human prostate cancer cells. Int J Food Sci Nutr 61: 324-336, 2010.

32. Xu C, Shen G, Chen C, Gelinas C and Kong AN: Suppression of NF-kappaB and NF-kappaB-regulated gene expression by sulforaphane and PEITC through IkappaBalpha, IKK pathway in human prostate cancer PC-3 cells. Oncogene 24: 4486-4495, 2005.

33. Bommareddy A, Hahm ER, Xiao D, et al: Atg5 regulates phenethyl isothiocyanate-induced autophagic and apoptotic cell death in human prostate cancer cells. Cancer Res 69: 3704-3712, 2009.

34. Wu X, Kassie F and Mersch-Sundermann V: Induction of apoptosis in tumor cells by naturally occurring sulfur-containing compounds. Mutat Res 589: 81-102, 2005

35. Morse MA, Amin SG, Hecht SS and Chung FL: Effects of aromatic isothiocyanates on tumorigenicity, O6-methylguanine formation and metabolism of the tobacco-specific nitrosamine 4-(methylnitrosamino)-1-(3-pyridyl)-1-butanone in A/J mouse lung. Cancer Res 49: 2894-2897, 1989.

36. Zhang Y, Kensler TW, Cho CG, Posner GH and Talalay P Anticarcinogenic activities of sulforaphane and structurally related synthetic norbornyl isothiocyanates. Proc Natl Acad Sci USA 91: 3147-3150, 1994

37. Powolny AA, Bommareddy A, Hahm ER, et al: Chemopreventative potential of the cruciferous vegetable constituent phenethyl isothiocyanate in a mouse model of prostate cancer. J Natl Cancer Inst 103: 571-584, 2011.

38. Kelloff GJ, Crowell JA, Hawk ET, et al: Strategy and planning for chemopreventive drug development: clinical development plans II. J Cell Biochem (Suppl 26): 54-71, 1996.
39. Yang MD, Lai KC, Lai TY, et al: Phenethyl isothiocyanate inhibits migration and invasion of human gastric cancer AGS cells through suppressing MAPK and NF-kappaB signal pathways. Anticancer Res 30: 2135-2143, 2010.

40. Lai KC, Huang AC, Hsu SC, et al: Benzyl isothiocyanate (BITC) inhibits migration and invasion of human colon cancer HT29 cells by inhibiting matrix metalloproteinase-2/-9 and urokinase plasminogen (uPA) through PKC and MAPK signaling pathway. J Agric Food Chem 58: 2935-2942, 2010.

41. Xiao D and Singh SV: Phenethyl isothiocyanate inhibits angiogenesis in vitro and ex vivo. Cancer Res 67: 2239-2246, 2007.

42. Lu KW, Chen JC, Lai TY, et al: Gypenosides inhibits migration and invasion of human oral cancer SAS cells through the inhibition of matrix metalloproteinase-2 -9 and urokinase-plasminogen by ERK $1 / 2$ and NF-kappa B signaling pathways. Hum Exp Toxicol 30: 406-415, 2011.

43. Hour MJ, Tsai SC, Wu HC, et al: Antitumor effects of the novel quinazolinone MJ-33: Inhibition of metastasis through the MAPK, AKT, NF-kappaB and AP-1 signaling pathways in DU145 human prostate cancer cells. Int J Oncol 41: 1513-1519, 2012.

44. Ohnishi Y, Lieger O, Attygalla M, Iizuka T and Kakudo K: Effects of epidermal growth factor on the invasion activity of the oral cancer cell lines HSC3 and SAS. Oral Oncol 44: 1155-1159, 2008.

45. Yang JS, Liu CW, Ma YS, et al: Chlorogenic acid induces apoptotic cell death in U937 leukemia cells through caspase- and mitochondria-dependent pathways. In Vivo 26: 971-978, 2012.

46. Lan YH, Chiang JH, Huang WW, et al: Activations of both extrinsic and intrinsic pathways in HCT 116 human colorectal cancer cells contribute to apoptosis through p53-mediated ATM/ Fas signaling by Emilia sonchifolia extract, a folklore medicinal plant. Evid Based Complement Alternat Med 2012: 178178, 2012.

47. Tsai SC, Huang WW, Huang WC, et al: ERK-modulated intrinsic signaling and $\mathrm{G}(2) / \mathrm{M}$ phase arrest contribute to the induction of apoptotic death by allyl isothiocyanate in MDA-MB-468 human breast adenocarcinoma cells. Int J Oncol 41: 2065-2072, 2012.

48. Kao WT, Lin CY, Lee LT, et al: Investigation of MMP-2 and -9 in a highly invasive A431 tumor cell sub-line selected from a Boyden chamber assay. Anticancer Res 28: 2109-2120, 2008.

49. Chen KT, Hour MJ, Tsai SC, et al: The novel synthesized 6-fluoro(3-fluorophenyl)-4-(3-methoxyanilino)quinazoline (LJJ-10) compound exhibits anti-metastatic effects in human osteosarcoma U-2 OS cells through targeting insulin-like growth factor-I receptor. Int J Oncol 39: 611-619, 2011.

50. Yang JS, Wu CC, Kuo CL, et al: Solanum lyratum extracts induce extrinsic and intrinsic pathways of apoptosis in WEHI-3 murine leukemia cells and inhibit allograft tumor. Evid Based Complement Alternat Med 2012: 254960, 2012.

51. Chiu YJ, Hour MJ, Lu CC, et al: Novel quinazoline HMJ-30 induces U-2 OS human osteogenic sarcoma cell apoptosis through induction of oxidative stress and up-regulation of ATM/ p53 signaling pathway. J Orthop Res 29: 1448-1456, 2011

52. Bjorklund $\mathbf{M}$ and Koivunen E: Gelatinase-mediated migration and invasion of cancer cells. Biochim Biophys Acta 1755: 37-69, 2005.

53. Bode W, Fernandez-Catalan C, Grams F, et al: Insights into MMP-TIMP interactions. Ann NY Acad Sci 878: 73-91, 1999.

54. Kalyankrishna S and Grandis JR: Epidermal growth factor receptor biology in head and neck cancer. J Clin Oncol 24 2666-2672, 2006

55. Zimmermann M, Zouhair A, Azria D and Ozsahin M: The epidermal growth factor receptor (EGFR) in head and neck cancer: its role and treatment implications. Radiat Oncol 1: 11, 2006.

56. Rogers SJ, Harrington KJ, Rhys-Evans $\mathrm{P}$, O-Charoenrat $\mathrm{P}$ and Eccles SA: Biological significance of c-erbB family oncogenes in head and neck cancer. Cancer Metastasis Rev 24: 47-69, 2005.

57. Jemal A, Murray T, Samuels A, Ghafoor A, Ward E and Thun MJ: Cancer statistics, 2003. CA Cancer J Clin 53: 5-26, 2003.

58. Lo HW and Hung MC: Nuclear EGFR signalling network in cancers: linking EGFR pathway to cell cycle progression, nitric oxide pathway and patient survival. Br J Cancer 94: 184-188, 2006.

59. Yarden Y: The EGFR family and its ligands in human cancer. signalling mechanisms and therapeutic opportunities. Eur J Cancer 37 (Suppl 4): S3-S8, 2001.

60. Temam S, Kawaguchi H, El-Naggar AK, et al: Epidermal growth factor receptor copy number alterations correlate with poor clinical outcome in patients with head and neck squamous cancer. J Clin Oncol 25: 2164-2170, 2007. 
61. Chung $\mathrm{CH}$, Ely $\mathrm{K}$, McGavran L, et al: Increased epidermal growth factor receptor gene copy number is associated with poor prognosis in head and neck squamous cell carcinomas. J Clin Oncol 24: 4170-4176, 2006.

62. Kim JH, Xu C, Keum YS, Reddy B, Conney A and Kong AN: Inhibition of EGFR signaling in human prostate cancer PC-3 cells by combination treatment with beta-phenylethyl isothiocyanate and curcumin. Carcinogenesis 27: 475-482, 2006.

63. Thomas GT, Lewis MP and Speight PM: Matrix metalloproteinases and oral cancer. Oral Oncol 35: 227-233, 1999.

64. Xiao D, Choi S, Lee YJ and Singh SV: Role of mitogen-activated protein kinases in phenethyl isothiocyanate-induced apoptosis in human prostate cancer cells. Mol Carcinog 43: 130-140, 2005.

65. Huong LD, Shin JA, Choi ES, et al: beta-Phenethyl isothiocyanate induces death receptor 5 to induce apoptosis in human oral cancer cells via p38. Oral Dis 18: 513-519, 2012.
66. Yang YM, Conaway CC, Chiao JW, et al: Inhibition of benzo(a) pyrene-induced lung tumorigenesis in $\mathrm{A} / \mathrm{J}$ mice by dietary $\mathrm{N}$-acetylcysteine conjugates of benzyl and phenethyl isothiocyanates during the postinitiation phase is associated with activation of mitogen-activated protein kinases and p53 activity and induction of apoptosis. Cancer Res 62: 2-7, 2002.

67. Xiao D and Singh SV: Phenethyl isothiocyanate-induced apoptosis in p53-deficient PC-3 human prostate cancer cell line is mediated by extracellular signal-regulated kinases. Cancer Res 62: 3615-3619, 2002

68. Hu R, Kim BR, Chen C, Hebbar V and Kong AN: The roles of JNK and apoptotic signaling pathways in PEITC-mediated responses in human HT-29 colon adenocarcinoma cells. Carcinogenesis 24: 1361-1367, 2003. 